\title{
Subjetividade e samba: a dor pede passagem
}

\author{
Subjectivity and samba: pain seeks passage
}

Subjetividad y samba: el dolor pide paso

Tânia Maia Barcelos

\section{Resumo}

Este artigo busca problematizar a subjetividade contemporânea, especialmente os modos hegemônicos de experimentação da dor, a partir de um encontro com o samba, gênero musical brasileiro, criado, oficialmente, nas primeiras décadas do século XX. O artigo parte da hipótese de que esse encontro pode potencializar a subjetividade brasileira nos processos de invenção e resistência à política do "evitamento da dor", tão presente no contexto do capitalismo cultural, que, nas últimas décadas, vem acionando novas estratégias de produção de subjetividade que capturam e mercantilizam os afetos. Nesse encontro, autores como Deleuze, Guattari, Rolnik, Jurandir Freire, entre outros, auxiliam a apreensão das letras e versos de samba como possibilidades de experimentação da dor, na contramão das formas predominantes, historicamente, na cultura moderna e ocidental.

Palavras-chave: subjetividade; contemporaneidade; samba; dor.

\begin{abstract}
This article aims to problematize contemporary subjectivity, especially hegemonic ways of experimenting pain, based on an encounter with samba - the Brazilian musical genre created officially in the first decades of the 20th Century. It puts forward the hypothesis that this encounter may reinforce Brazilian subjectivity in the processes of invention and resistance to the "pain avoiding" policy, so strong in the context of cultural capitalism. In the last decades, that policy has worked out subjectivity production strategies that capture and commercialize affection. In that encounter, authors such as Deleuze, Guattari, Rolnik and Jurandir Freire Costa, among others, help understanding samba lyrics and verses as possibilities of experimenting pain, in the opposite direction of forms historically predominant in western modern culture.
\end{abstract}

Key-words: subjectivity; contemporaneity; samba; pain.

Texto recebido em agosto de 2008 e aprovado para publicação em abril de 2010.

Doutora em Psicologia Clínica pela Pontifícia Universidade Católica de São Paulo, professora da Universidade Federal de Goiás (UFG).E-mail: taniamaia.barcelos@gmail.com. 


\section{Resumen}

Este artículo busca cuestionar la subjetividad contemporánea, especialmente, los modos hegemónicos de experimentación del dolor, a partir de un encuentro con la samba - género musical brasileño, creado oficialmente en las primeras décadas del siglo XX. El artículo parte de la hipótesis que de ese encuentro se puede potenciar la subjetividad brasileña en los procesos de invención y resistencia a la política de "evitar el dolor", tan presente en el contexto del capitalismo cultural que, en las últimas décadas, viene accionando nuevas estrategias de producción de subjetividad que capturan y mercantilizan los afectos. En ese encuentro, autores como Deleuze, Guattari, Rolnik, Jurandir Freire, entre otros, auxilian a la aprehensión de las letras y versos de la samba como posibilidades de experimentación del dolor en la dirección contraria a las formas predominantes, históricamente, en la cultura moderna y occidental.

Palabras clave: subjetividad; contemporaneidad; samba; dolor.

\section{A dor pede passagem}

Tire seu sorriso do caminho

Que eu quero passar com a minha dor

ए ste texto parte da hipótese de que as forças que perpassam o samba, sejam de alegria, de resistência ou de criação, podem ser fortes aliadas da subjetividade ${ }^{2}$ contemporânea brasileira na luta por novas possibilidades de vida. Ou seja, o encontro com esse gênero musical que emergiu nas primeiras décadas do século XX, passou a ser considerado símbolo nacional nos anos 30 e hoje é capaz de arrastar multidões pode potencializar essa subjetividade, não somente na perspectiva da invenção, mas também na perspectiva da resistência. Tal hipótese é fortalecida, sobretudo, quando experimentamos estranhamentos no encontro com o samba que nos forçam a pensar. Estranhamentos, por exemplo, como os que sentimos ao ouvir esses versos de Nelson Cavaquinho e Guilherme de Brito: "Tire seu sorriso do caminho, que eu quero passar com a minha dor".

Soa estranho pedir passagem para a dor, numa cultura como a nossa, na qual se produz subjetividades que evitam a contaminação pelos afetos tristes

\footnotetext{
Nelson Cavaquinho, Guilherme de Brito e Alcides Caminha. A flor e o espinho. CD Nelson Cavaquinho, Coleção MPB Compositores, n. 26. RGE, 1997.

Subjetividade, aqui, refere-se aos modos de existência construídos historicamente e vividos por indivíduos em suas existências particulares. São provisórios e abertos às linhas de fuga, as quais possibilitam novas configurações existenciais (Cf. Guattari e Rolnik, 1986).
} 
e intoleráveis e tornam-se cegas e surdas aos apelos do corpo. É estranho pedir passagem para a dor numa cultura que, historicamente, relaciona-se com ela de diferentes maneiras, desde sustentá-la para ganhar a salvação em outra vida, até negá-la, na tentativa de conquistar uma forma de vida ideal, sem abalos e desassossegos; numa cultura em que ficar doente, muitas vezes, é motivo de constrangimento e vergonha, outras vezes, é estratégico, já que, por certas doenças, é possível obter algumas vantagens.

Pedir passagem para a dor talvez soe mais estranho ainda nos dias atuais, cada vez mais difíceis de tolerá-la por causa das inúmeras possibilidades que temos de evitá-la. Diferente de outros contextos, em que a dor era vivida de outras maneiras.

Como afirma Sant'Anna (2001), antes da descoberta da anestesia, no século XIX, a dor física tinha vários sentidos que a enobreciam.

Resistir bravamente à dor durante a extração de um dente, por exemplo, contribuía para a boa formação do caráter, especialmente quando se tratava do sexo masculino. Muitas narrativas que expunham as penas sofridas em cirurgias e as dores vividas em acidentes e doenças continham uma função pedagógica. Ensinavam a valorizar o ser humano, principalmente as virtudes da coragem e da persistência. No lugar de ser um limite para a vida, a dor mostrava os limites do corpo [...]. Como se naqueles tempos fosse mais tolerável do que hoje ouvir os discursos sobre a dor (Sant'Anna, 2001, p. 38).

Não que em outros tempos se fizesse apologia da dor, argumenta Sant'Anna (2001), mas ela era acolhida de outros modos, estranhos em nossa época, de extrema naturalização da saúde e do prazer infinito. Épocas em que combinamos saúde e prazer de diversos modos - dietas, ginásticas, tratamentos de beleza, psicoterapias, viagens, etc. - em busca de uma vida saudável e politicamente correta, de olho na beleza, na boa forma e na longevidade.

Em épocas de promessa de bem-estar contínuo, "ser jovem, saudável, longevo e atento à forma física tornou-se a regra científica que aprova ou condena outras aspirações à felicidade" (Costa, 2004, p. 190). Como afirma Jurandir Freire Costa (2004), somos tolerantes ou complacentes com tantas coisas que acontecem ao nosso redor, desde que não desequilibrem nossas taxas de colesterol. ${ }^{3}$

\footnotetext{
Para Jurandir Freire Costa (2004), a personalidade somática de nosso tempo, em oposição à personalidade neurótica e à personalidade narcísica, tem, na imagem social do corpo, o suporte, por excelência, do caráter ou da identidade. A cada episódio de sofrimento, ela reage como se algo de extraordinário tivesse acontecido, causado por alguma falha nos cuidados com o corpo que passou a ser uma vitrine compulsória de seus vícios e virtudes.
} 
Para o autor, a obediência às novas formas de disciplinarização do corpo nos deixa em constante vigília.

Qualquer comentário sobre hábitos alimentares, por exemplo, desencadeia, em geral, uma tagarela, bizarra e infantilizada competição sobre quem faz mais exercícios; quem come menos gordura; quem é capaz de perder mais quilos em menos tempo; quem ingere mais vegetais, alimentos e fármacos naturais, etc. (Costa, 2004, p. 199).

Os que não jogam o jogo são vistos como desviantes ou problemáticos, pois não apostam na "boa forma" e na qualidade de vida. Ao contrário, "ficam para trás na maratona da fitness: obesos; manchados de pele; sedentários; envelhecidos precocemente; tabagistas; não siliconados; não lipoaspirados, etc." (Costa, 2004, p. 196).

$\mathrm{Na}$ atualidade, não é somente o limiar suportável da dor física que diminuiu. Os desconfortos psíquicos também diminuíram progressivamente a partir dos anos 50 do século XX, com o desenvolvimento da psicofarmacologia, que abriu novas possibilidades de relacionamento com a dor mental. Segundo Birman (2000), a população passou a ser medicada numa escala sem precedentes. A angústia, a tristeza, a variação do humor e demais desconfortos psíquicos passaram a ser eliminados por psicofármacos específicos para cada quadro sintomático ou síndrome psicopatológica.

Os avanços da indústria farmacêutica foram decisivos na política do "evitamento da dor", sustentada, também, pela indústria do narcotráfico. Para Birman (2000), essas indústrias mantêm entre si uma relação secreta e perigosa, caminhando na mesma direção, moral e política, apesar das diferenças que cada uma apresenta. A química das drogas pesadas promove "o gozo por si mesmo como valor" (p. 243), por intermédio das viagens pelo imaginário, e os saltos mágicos compatíveis com as performances exigidas pela sociedade. Em contrapartida, a prática medicamentosa seda a angústia e elimina as excitações excessivas, as paixões depressivas e os humores intempestivos, transformando sujeitos deprimidos e panicados em cidadãos efetivos da sociedade do espetáculo. Essa transformação tenta evitar os supostos fracassos desses sujeitos e faz com que eles transitem conforme é exigido socialmente: com "o peito inflado e o eu obeso de si mesmo" (Birman, 2000, p. 247).

Tanto na indústria farmacêutica como na indústria do narcotráfico prevalece a política do "evitamento da dor". Como argumenta Birman (2000), a cultura contemporânea ocidental dos últimos anos não admite mais personagens sofrentes e desesperados. 
O que interessa, agora, é a estetização da existência e a inflação do eu, que promovem uma ética oposta à do sofrimento. Enfim, por esse caminho, pode-se entender a cultura do evitamento da dor promovida pela medicina e pela indústria de drogas pesadas, pois, por seu intermédio, a magia do silêncio do sofrimento psíquico está sempre em pauta (Ibidem, p. 244).

O autor lembra que não é por acaso que, nas últimas décadas, houve um aumento crescente das toxicomanias produzidas pela indústria medicamentosa e pelo narcotráfico. Toxicomanias como efeitos de imperativos éticos que prescrevem como devemos ser: consumidores frequentes de drogas de toda espécie que visam a eliminar dores e sofrimentos da subjetividade.

Para se proteger dos desconfortos do mundo contemporâneo, a subjetividade acaba se viciando em diversos tipos de drogas que o mercado oferece. Segundo Rolnik (1997), além do vício pelas drogas farmacológicas e do narcotráfico, ela vicia em outras modalidades de drogas, tais como a mídia, a literatura de autoajuda, o esoterismo, as tecnologias diet/ligh e certas formas de terapias e religião.

Todas essas drogas proporcionam algum tipo de alívio da subjetividade. Se as drogas pesadas oferecem miragens de onipotência e velocidade compatíveis com o tempo hegemônico, a literatura de autoajuda e esotérica, assim como algumas religiôes ensinam como exorcizar o malestar que a desconforta. As tecnologias diet/light fornecem fórmulas de purificação do corpo, tendo em vista maximizar sua flexibilidade. A mídia, por sua vez, vicia as pessoas por glamour, por meio das figuras que veicula, diariamente, cujos perfis se apresentam imunes aos desassossegos. Os viciados nessa droga, afirma Rolnik (1997, p. 22), "vivem dispostos a mitificar e consumir toda imagem que se apresente de forma minimamente sedutora, na esperança de assegurar seu reconhecimento em alguma órbita do mercado”.

Assim como a subjetividade, o corpo, ao mesmo tempo em que tenta sustentar o "evitamento da dor", denuncia essa política, veementemente, por meio de novas queixas e novos sintomas. Na surdina, ele grita por socorro e mostra que não aguenta mais: nem suas dores, seus pesos, suas fadigas $^{4}$, nem a submissão a uma subjetividade que lhe impõe diversos tipos de aprisionamentos e formas de vida. Os corpos não aguentam mais

\footnotetext{
4 Machado (2004) lembra que a síndrome da fadiga crônica, que aparece como uma doença sem explicação precisa, pode ser vista como uma expressão das configuraçôes subjetivas que se engendram na atualidade.
} 
sucumbir aos controles que os fixam nem tampouco aos controles que os flexibilizam excessivamente. Não suportam mais se fechar para outros corpos, nem se expor, demasiadamente, a tantas informações, técnicas de controle, novidades e estranhamentos. Haja corpo para tanto excesso e tanto cansaço - de filas, propagandas, produtos de toda espécie espalhadas pelas ruas e lojas da cidade, tais como roupas, calçados, comidas, CDs, celulares, souvenirs, etc.

Os excessos e cansaços evidenciam sensações de impotência, mas também anunciam novas potências do corpo.

Isto é, o cansaço como expressão da ponta extrema do entorpecimento que impede o sentir-se cansado, e a sensação de cansaço como expressão do sentir que possibilitaria o desejo de transformação desse estado de coisa, experiência que traria à tona uma falência das redes de captura (Machado, 2004, p. $165)$.

Nessa perspectiva, a fadiga ou o cansaço do corpo são gritos de socorro que expressam sua sensibilidade ao sofrimento, condição primeira de estar exposto às forças do mundo e de ser afetado por outros corpos. Como bem afirma Lapoujade (2002), o "eu não aguento mais" não é signo de fraqueza de potência alguma, mas a expressão da resistência do corpo às imposiçóes históricas de organização e de subjetivação. Resistindo é que o corpo exprime uma potência própria, que implica sentir o sofrimento e suportar o insuportável. É essa potência que o leva a "não aguentar mais" e evitar a dor excessiva; ao mesmo tempo, impede o corpo de negá-la ou de anestesiá-la.

O que está em jogo nessa potência é encontrar uma saúde no sofrimento, ou seja, ser sensível a ele sem adoecer a vida; experimentá-lo não como doença, mas como um meio para a saúde, na perspectiva de otimizar as funções vitais do corpo. Contrário à saúde focada na busca de um corpo dinâmico, musculoso, flexível e produtivo, tendo em vista melhor adaptá-lo ao sistema. Trata-se de uma frágil saúde que radicaliza a potência da vida, presente, por exemplo, no artista e no escritor, em função de ter visto e ouvido coisas, demasiadamente atormentadoras e pouco suportáveis a uma "gorda saúde dominante" (Deleuze, 2001). A frágil saúde do corpo é inseparável da exposição ao sofrimento e da resistência a ele, não para suportá-lo, desmedidamente, mas para impedir que o sofrimento o destrua.

Não seria, também, essa frágil saúde do corpo que leva o sambista a pedir passagem para a dor e denunciar, de certa maneira, a política de "evitamento" e intolerância do sofrimento presente na atualidade? 


\section{Dor e ternura}

O sambista explicita a potência de resistência e invenção do corpo e da subjetividade em vários momentos. Como poeta, quando ele

Se encontra sozinho num canto qualquer do seu mundo I

Vibram acordes, surgem imagens

Soam palavras, formam-se frases / Mágoas

Tudo passa com o tempo / Lágrimas

São as pedras preciosas da ilusão

Quando surge a luz da criação no pensamento

Ele trata com ternura o sofrimento

E afasta a solidão. ${ }^{5}$

Sem evitar ou amaldiçoar o sofrimento e sem permitir que ele despotencialize seu corpo, o compositor/sambista trata a dor com ternura - afeto brando e suave que não exige grandes transportes -, compondo de forma errante e alucinada. É desse modo que ele esmiúça a dor e busca outros rumos para a vida.

Compor, saibam vocês,

É mais que um desatino

Esmiuçar a dor, fio a pavio,

Ofício que deságua o sofrimento,

É escoar-se inteiro como um rio,

E eu me ponho a compor feito um cigano

Que busca noutra luz seu próprio lume. ${ }^{6}$

Nos versos de samba, a dor ganha um sentido estético. "A luz da criação no pensamento" faz com que ela seja esmiuçada e escoada "com a coragem de um médico que inocula, em si mesmo, poçôes do mal que quer combater" (Dias, 1994, p. 50). Por ritornelos diversos, que promovem uma repetição intensiva do sofrimento, a dor ganha novos sentidos.

Cada volta que a dor dá dentro do peito lhe mostra um novo aspecto do sofrimento e um diferente aspecto do que perdeu e da pessoa perdida. Repetição que lhe proporciona não a cura dos males, mas a capacidade de digeri-los (Loc. cit.).

Digerindo e esmiuçando a dor "fio a pavio", o sambista esquece certos estados de paixão que envenenam sua alma, sem os aceitar passivamente

\footnotetext{
5 Paulinho da Viola. Quando bate uma saudade. CD Eu canto samba. BMG, 1989.

6 Paulinho da Viola e Hermínio Bello de Carvalho. Cantoria. Cd Eu canto samba. BMG, 1989.
} 
como se estivesse exposto a um sofrimento estéril. A dor não é vivida como um fardo ou um argumento contra a existência. Ao contrário, ela se torna um forte motivo para a subjetividade mudar de pele: "A minha alma sofrida quer descansar sem saber como abandonar de vez esta pele ferida, maltratada e curtida" ${ }^{7}$

O sofrimento é experimentado como um "excitante da vida" ou "um argumento a seu favor" (Deleuze, 2001). Depois de tratá-lo com ternura, o sambista reconstitui a vida, esteticamente, afirmando, com tranquilidade, que chora por tudo que rememora, mas depois,

Lavo o meu peito e melhoro

Encho o meu copo e o devoro

Tirando essa angústia de mim

Depois canto

Limpo os vestígios do pranto

Pago a despesa e levanto

Eu vou sair por aí

Pelas ruas da noite sem fim

Saciado / No rosto um vento gelado

Apunhalando o passado

Reconstituindo a vida

Mais leve / Mostrando a dor como é breve

Quando você, solidão / Me faz sentir em paz. ${ }^{8}$

É essa postura que deixa o poeta à vontade para brincar com a dor e desafiála: seu tempo é breve e, se "me encontrar, numa esquina qualquer, já não vai me reconhecer"10. Mas para que isso seja possível, é necessário "apunhalar o passado", digerir os sentimentos que envenenam a subjetividade e conectá-la a uma força plástica que aciona a memória inventiva: o esquecimento.

Avesso a uma memória viciada, passiva e inerte, o esquecimento permite anular os efeitos das marcas envenenadoras, que produzem ruminações improdutivas e paralisam o desejo como forma de expansão da vida. Como afirma Lins (2000, p. 51), é preciso:

Esquecer para não morrer da memória! Esquecer para não deixar que o torturador, o violento, o déspota riam ao constatar que a vítima de ontem, hoje, livre das amarras e dos golpes sádicos, continue sendo o refém infeliz e ressentido, o adorador de seu

\footnotetext{
Paulinho da Viola e Capinan. Sofrer. Paulinho da Viola. EMI-Odeon, 1978.

8 Elton Medeiros e Paulo César Pinheiro. Conversa com a solidão. Cd Aurora da Paz. Rio de Janeiro: Rob Digital, 2001.

9 Elton Medeiros e Salgado Maranhão. Recato. Cd Aurora da paz. Rio de Janeiro: Rob Digital, 2001.
} 
algoz, atado à impossibilidade de esquecer o esquecimento, que fez da memória passiva, sua própria prisão... e seu túmulo!

Se o ressentido caracteriza-se por uma prodigiosa memória e pelo poder de conservar, o criador se define pela faculdade de esquecer e pelo poder de criar. $\mathrm{O}$ ressentido conserva a vida, mas impede que ela seja reinventada. Sua memória excessiva é venenosa, e seu processo de digestão é lento, pesado e difícil de ser metabolizado. É como se ele nunca estivesse pronto para viver o presente e o novo. As lembranças lhe ulceram a alma e alimentam suas feridas. Por isso, ele não exorciza os demônios que voltam, constantemente, para encarnar novas formas de existência (Dias, 1994, p. 36). ${ }^{10}$

O criador, ao contrário, sabe esquecer e não leva muito a sério seus contratempos e malfeitos. Se ele esquece, se recorda, pois é só assimilando o passado que se torna possível destruir certas formas de vida e construir outras. Para impedir a fixação das marcas envenenadoras da memória, o criador se torna inapto tanto para o perdão como para a culpa. Ele esquece, não para perdoar, mas para sustentar outra memória e continuar desejando a vida, acreditando que

O vento é quem tira a poeira de tudo

A gente lamenta e depois reconhece

Que o amor não se acaba nas dores do mundo. ${ }^{11}$

Ao tratar a dor e o sofrimento com ternura, o sambista faz alianças com o devir e exprime uma discreta alegria da potência de resistir. Ele diz "não" à exposição excessiva ao sofrimento e, também, à política do "evitamento da dor" que despotencializa a vida. Tal postura nada tem a ver com masoquismo ou indiferença aos estranhamentos, pois requer uma conexão do corpo àquilo que lhe é próprio: sua condição de afetar e ser afetado, inclusive por aquilo que lhe atinge em demasia, afinal, a abertura ao estrangeiro e à alteridade depende, também, da capacidade do corpo evitar a violência que o destrói de vez (Pelbart, 2003).

Em tempos de "evitamento da dor" e de pouca positividade à doença, por causa da ditadura da saúde adequada ao capitalismo turbinado, o samba nos dá uma dica importante: é possível resistir às

\footnotetext{
${ }^{10}$ Ver também Ferraz (2002) e Dias (2004).

${ }^{11}$ Paulinho da Viola. Pra jogar no oceano. Cd Paulinho da Viola e Ensemble. WDR, 1993.
} 
formas predominantes de experimentação do sofrimento que o usam como argumento contra a existência ou o evitam na tentativa de negar a dimensão trágica da vida. É possível experimentar a dor como uma crueldade inevitável, a favor dos processos de criação e não em prol de lamentações e preservação de formas caducas de existência ou seduzidas por devires tolos, imersos no novo, sem resistência alguma.

Essa dica valiosa do samba atualiza o exercício da vida como criação e resistência, imprescindível no contexto do capitalismo contemporâneo, que dissocia essas duas potências, instrumentalizando a força de invenção e anulando as estratégias de resistência (Rolnik, 2004). A atualização desse exercício garante a expansão, a diferenciação da vida e fortalece as linhas de fuga da subjetividade brasileira diante das políticas de existência impostas no contexto atual, cada vez mais caras e insuportáveis aos nossos corpos.

É isso que o sambista exercita quando trata a dor com ternura, ludicidade e a coloca a serviço da afirmação da vida com tudo que ela comporta. Talvez seja isso também que se mobiliza em nossos corpos, no encontro com o samba, especialmente com os versos de Nelson Cavaquinho e Guilherme de Brito. Afinal, nesse encontro, vislumbramos outras possibilidades de escuta e experimentação da dor na contramão dos modos predominantes. Nesse encontro também somos contagiados por outros modos de afetar/ser afetado e levados a fortalecer a crença na força de resistência, tão tímida, em tempos de exaustão, fadiga, descrença e de vidas precárias em várias partes do planeta. Tempos difíceis, mas ainda possíveis para ouvir e cantar com Zeca Baleiro:

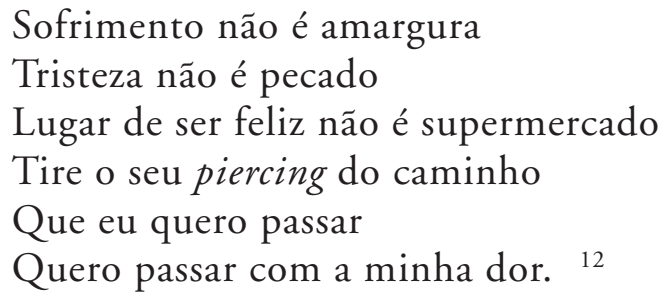

Se o pedido de passagem para a dor causava estranhamento e desconforto no início do texto, agora esse pedido é escutado como um apelo vital do corpo e da subjetividade que não aguentam mais o preço da política do evitamento da dor, tão presente na atualidade. Ou seja, a dor já começa a conquistar passagem:

\section{Tire seu sorriso do caminho!}

${ }^{12}$ Zeca Baleiro. Piercing. Vô imbolá álbum. MZA/Universal Music,1999. 


\section{Referências}

Birman, J. (2000). Mal-estar na atualidade: a psicanálise e as novas formas de subjetivação. Rio de Janeiro: Civilização Brasileira.

Costa, J. F. (2004). O vestígio e a aura: corpo e consumismo na moral do espetáculo. Rio de Janeiro: Garamond.

Deleuze, G. (2001). Nietzsche e a Filosofia. 2. ed. Tradução de António M. Magalhães. Porto: Rés-Editora.

Dias, R. M. (1994). As paixóes tristes: Lupicínio e a dor-de-cotovelo. Rio de Janeiro: Leviatã Publicaçôes.

Dias, R. M. (2004). A vida como vontade criadora: por uma visão trágica da existência. In: Fonseca \& Engelman (org.). Corpo, arte e clínica. (pp. 131146). Porto Alegre: Editora da UFRGS.

Ferraz, M.C.F. (2002). Nove variaçôes sobre temas nietzschianos. Rio de Janeiro: Relume Dumará.

Guattari, F; Rolnik, S. (1986). Micropoliticas: cartografias do desejo. Petrópolis: Vozes.

Lapoujade, D. (2002). O corpo que não aguenta mais. In: Lins, D. \& Gadelha, S. (org.). Nietzsche e Deleuze: que pode o corpo. (pp. 81-90). Rio de Janeiro: Relume Dumará.

Lins, D.; Costa, S. G.; Veras (org.). (2000). Nietzsche e Deleuze: intensidade e paixão. Rio de Janeiro: Relume Dumará.

Machado, L. D. (2004). Capitalismo e configurações subjetivas. In: Abdalla \& Barros (org.). Mundo e sujeito: aspectos da globalização. (pp. 164-171). São Paulo: Paulus.

Pelbart, P. P. (2003). Vida capital: ensaios de biopolitica. São Paulo: Iluminuras.

Rolnik, S. (1997). Toxicômanos de Identidade: subjetividade em tempo de globalização. In: Lins, D. (org.). Cultura e subjetividade: saberes nômades. (pp. 19-24). Campinas: Papirus.

Rolnik, S. (2004). "Fale com ele" ou como tratar o corpo vibrátil em coma. In: Fonseca, T. M. G.; Engelman, S. (org.). Corpo, arte e clínica. Porto Alegre: Editora da UFRGS.

Sant'Anna, D. (2001). Corpos de passagem: ensaios sobre a subjetividade contemporânea. São Paulo: Estação Liberdade. 